reached a maximum a distressed shudder went through the audience.

The book also emphasizes the interactions of science, politics and power which, at the end of a century dominated by military and space confrontation and the arms race, are obviously very strong. But the authors express different opinions on the plausibility of eliminating the nuclear danger from the world. The relationships between science and art are also briefly touched upon, but not too convincingly. Is it really science that influences art, or rather the object of science, that is, nature?

The general impression left by Carl Sagan's Universe is that, if mankind has not been given any centrality (only the merits of his actions, as Sagan says, may sometimes give him a justified feeling of importance), then science has certainly become central to mankind. Ann Druyan wonders whether democracy can exist without science.

The question raises the issue of whether, as science improves, it should be applied to encompass all aspects of human life. Sagan once proposed a position on abortion based on a purely scientific approach. His argument was logical and perfectly defensible, but is it the right approach to the problem? What about a scientific analysis of love, emotions, freedom or ethical behaviour? Regrettably, these issues are not addressed in the book.

Yet Carl Sagan's Universe, through the diversity of its contents and the generally high standard of its articles, remains a very fine piece of work that will interest a wide range of readers.

Emmanuel Lellouch is at the Observatoire de Meudon, F-92195 Meudon, France.

\section{How we feel}

\section{Friday's Footprint: How Society Shapes the Human Mind}

by Leslie Brothers

Oxford University Press: 1997. Pp. 187.

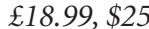

\section{What Emotions Really Are: The Problem of Psychological \\ Categories}

by Paul E. Griffiths

University of Chicago Press: 1997. Pp. 286. $\$ 27.50, £ 21.95$

\section{Ray Dolan}

The common theme of these two books is human emotion. Friday's Footprint explores the contribution of emotion to the shaping of a sense of self. What Emotions Really Are provides a dense exploration of our vernacular concepts of emotion. Both books, in their own ways, are important contributions to this expanding and important area of enquiry.

The title of Friday's Footprint turns out to be an oblique reference to the fateful encounter in Robinson Crusoe. It echoes the author's longstanding interest and belief in the social basis of mental life. Leslie Brothers' conjecture that socialization is central to the development of a concept of self and others is bolstered by data from primate and human pathological studies. The latter include syndromes such as Capgras's, in which a person comes to believe that somebody close to them has been replaced by a physically identical double, and infantile autism, which is proposed to represent a failure to develop a concept of others.

In keeping with a social interactionist view of mind, Brothers proposes that brain circuitry associated with emotional and evaluative processing is central in the development of a sense of self. An important idea is that a dedicated neural circuit, referred to as an editor, is specialized for processing behaviourally relevant aspects of the social environment.

This editor is not some high-level central

system but a mechanism that signals the adaptive value of incoming sensory signals. The neural structure best fitted to meet the necessary requirements is the amygdala. Visual signals derived from the human face are put centre stage in view of its importance in emotional expression, paralinguistic display and verbalization.

What comes as a surprise is that Brothers has profound difficulties with the entire concept of emotion. Anathema to her is the implicit idea that emotion is an attribute of an isolated mind rather than, in her view, an expression of evolved mechanisms for communication and behavioural regulation. Much hostility is expressed towards the influential proposal for a fractionation of emotion into discrete subtypes as implicit in the concept of basic emotions. Brothers' ideas in this respect hark back to those of the behaviourist philosopher Gilbert Ryle, particulary in her formulation that what is distinct about emotions is their associated action tendencies. Just because speakers of
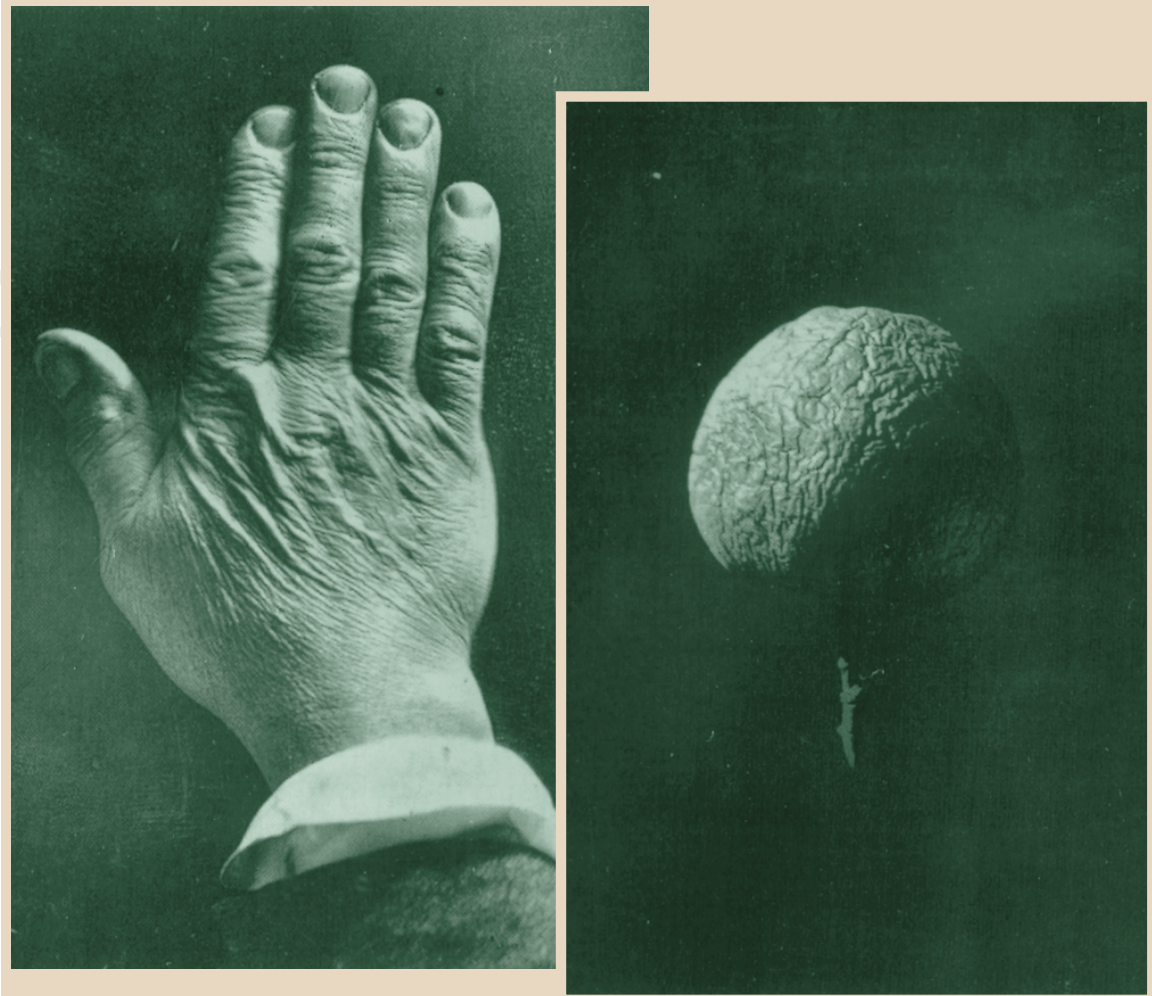

\title{
Scientific disciples of the artificial eye
}

One of the challenges of early photography was capturing the vast and intangible nature of astronomical objects. A novel approach was taken in a fascinating 1874 publication entitled The Moon, Considered as a Planet, $A$ World, and $a$ Satellite by the Scottish engineer James Nasmyth and the astronomer James Carpenter. Seeking to "educate the eye" about the "marvellous details" of the Moon, the authors based their book on drawings, astrophotographs and photographs of plaster models. They made visual propositions about surface formations analogous to those of the Moon, using, for example, the pictures shown here of a wrinkled hand and apple.

This is but one of the many intriguing stories about the use of photography in science that are told in the richly illustrated Beauty of Another Order by Ann Thomas, with additional essays by M. Braun, M. Cazort, M. Kemp, J. P. McElhone and L. J. Schaaf (Yale University Press, \$50, £40). 
English tactitly agree on the use of the word emotion, that does not guarantee its neurobiological validity.

In What Emotions Really Are, Paul Griffiths addresses the meaning of vernacular categories of emotion. Books on emotion often get bogged down in repetitive distillations of the multiple accounts of emotion that span the social to the biological. Griffiths's approach is refreshing in that he gets to the heart of the matter by dismissing as inadequate accounts of emotion subsumed by the general umbrella term of 'propositional attitudes'.

Griffiths also argues persuasively that cognitive theory explains very little about emotions. Emotional responses do not adjust themselves as readily as belief when new information about the environment is acquired. An example of this lack of fit between an emotional response and conscious evaluation would be a phobia. Griffiths echoes Brothers in identifying vernacular categories as a source of conceptual confusion and the absence of a priori reasons to assume that these categories have a necessary existence independent of language. A scientific psychology requires the refinement of emotion concepts to serve explanation and induction usefully.

Griffiths proposes that the general category of emotion should be replaced by, at a minimum, two distinct concepts. One would subsume the affect programs corresponding roughly to vernacular concepts of surprise, anger, fear, sadness, joy and disgust. The unity of this group is reflected in the fact that the associated affects are complex, coordinated and largely automated response patterns indexed in facial, musculoskeletal, vocal and autonomic nervous system outputs.

It should be stressed that affect programs do not explain all instances of the corresponding vernacular concepts. For instance, anger can vary from an affect program manifesting as spontaneous rage to more complex states as in plans for longterm redress of a wrong.

The latter type would best be subsumed under a second concept of emotion, distinct from the affect programs, termed the higher cognitive emotions, which account for emotions such as envy and shame. This second category describes what Griffiths terms irruptive motivations designed to enforce commitment to behaviourial strategies that would not fit with the calculations of selfinterest.

The higher cognitive emotions are also characterized by their ability to access beliefs and desires. In this regard, higher cognitive emotions are more flexible in expression than the highly stereotyped responses of affect programs.

Griffiths accepts that there is no adequate framework for research into higher cognitive emotions but rejects any assumption that they represent an elaboration of more basic affects. His assumption is that, like the basic affects, these emotions are amenable to an evolutionary explanation.

It is difficult to do justice to Griffiths in a short review. His analysis of the concept of emotion and his proposal for the future direction of the field is the most compelling and best argued I have read. What Emotions Really Are makes a strong claim to be one of the best books to have emerged on the subject of human emotion.

Ray Dolan is in the Wellcome Department of

Cognitive Neurology, Institute of Neurology, Queen Square, London WC1N 3BG, UK.

\section{Shadow history}

\section{To Light Such a Candle}

by Keith J. Laidler

Oxford University Press: 1998. Pp. 384. £25

\section{Peter Harman}

In a series of historical accounts, drawn largely from developments in the physical sciences since the eighteenth century, Keith J. Laidler seeks to shed light on the relationship between science and technology. Despite the religious resonances of the title of this book, to which its epigraph draws attention, the 'candle' is that of the 'pure' science that has transformed material life during the past two centuries.

Laidler is concerned to study the past for its bearing on public attitudes and policy in the present. In illustration of his endeavour, he provides historical narratives of seven episodes in the history of science and technology: on James Watt, the steam engine and thermodynamics; on the history of photography; on Michael Faraday and electric power; on James Clerk Maxwell and radio transmission; on J. J. Thomson and the age of electronics; on the Braggs and molecular architecture, leading to the discovery of the structure of DNA and its implications; and on Albert Einstein, relativity and the quantum theory, leading to nuclear power and the atomic bomb.

Each chapter provides a historical narrative of a scientific quest, affirming the vitality of 'pure' science as an intellectual endeavour, and tracing the technological consequences of research, which were often not anticipated by the original protagonists.

Laidler states an intention to bridge the gulf between the perceptions of scientists and nonscientists about the very nature of the significant achievements of science during the past few centuries. He points out that, whereas scientists might point to Maxwell's field theory or quantum mechanics as examples of scientific advances, nonscientists would be apt to cite the invention of radio, colour television and the like.
Laidler's response to this discrepancy in perception, and to public ignorance, is couched in terms of a defence of research science as the 'candle' that has fired technology. He maintains that pure research should be judged on its own merits, that technology should be based on pure science and that "decisions about science and technology must be based on a careful consideration of all the factors involved".

These propositions are stated as 'conclusions', and although the first two seem bland and the third opaque, they are perfectly acceptable, if scarcely striking, as statements of opinion. The problem here is that, although Laidler's concerns and aims inspire sympathy, and his resolute defence of science as an intellectual quest can be amply documented, the argument of the book, except by broad inference, does little to establish his stated conclusions.

The substance of the book is given over, in Laidler's words, to "a 'popular' exposition of some aspects of science and technology". He proceeds by means of historical case studies, but his presentation is beset with difficulties. He relies on secondary sources, hardly surprising given the breadth of coverage in his book, but their use is not shaped by scholarly discrimination, and his text frequently meanders down seemingly irrelevant byways.

Moreover, the historical narrative is marred by errors and confusions, and although this is merely unfortunate in a popular study, it diminishes the authority of a work that aims to establish some broader thesis, as is the case here. But this thesis, on the nature and relationship of pure and applied science, is here only stated and addressed in general terms.

To Light Such a Candle therefore seems to fall between several stools. The historical analysis is not of a type to contribute effectively to a deeper understanding of the historical relationship of science and technology and their bearing on current public policy. Nor is this issue properly analysed. The reader is urged to conclude that, because science has had unexpected technological products, pure science should be encouraged as a way of securing future practical benefits. This may be reasonable, but it is scarcely original or striking, nor is it here rigorously argued.

The format of the book is attractive, and its argument provides a fairly accessible, but not always accurate or cogent, introductory exposition of topics in the history of science. But, given the fairly technical level of the text, it is likely to appeal to scientists rather than to the nonscientists whose confusion about the relationship between science and technology the author has sought to clarify.

Peter Harman is in the Department of

History, University of Lancaster, Lancaster LA1 4YG, UK. 